Recibido: septiembre de 2015

Aprobado: octubre de 2015

DOI:

http://dx.doi.org/10.15332/rev.m.v12il.1928

\section{DIAGNÓSTICO Y PROPUESTAS DE ACCESIBILIDAD UNIVERSAL Y DISEÑO PARA TODOS EN EL PARQUE DE LOS NIÑOS DE BUCARAMANGA*}

Leonardo Enrique Díaz Suárez** - Universidad Santo Tomás, Colombia
Monumento "Clavijero del tiple" en el Parque de los Niños, Bucaramanga.

Fuente: Leonardo Enrique Díaz Suárez, 2015

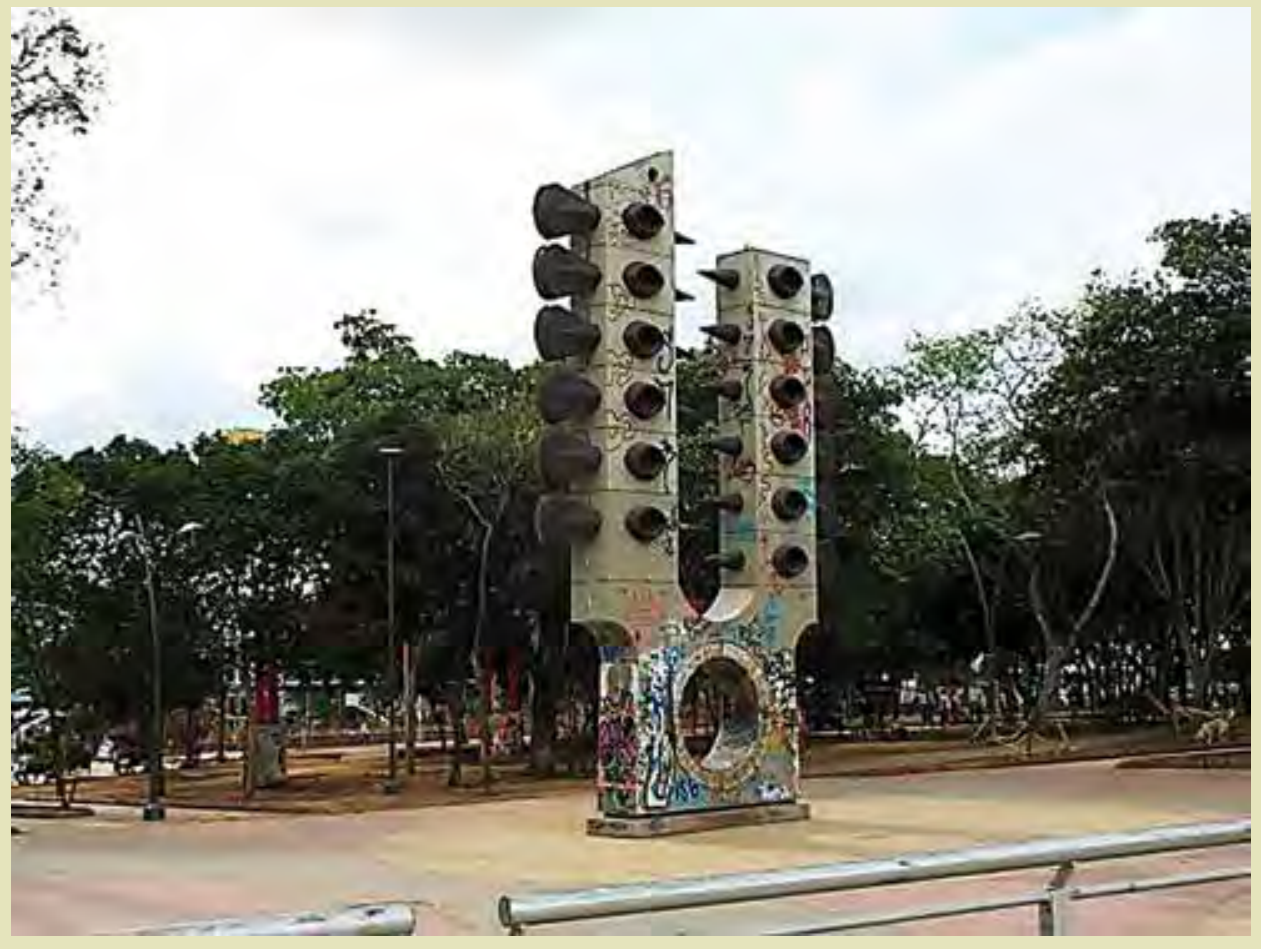

\section{RESUMEN}

La búsqueda de la igualdad de oportunidades en el espacio público de Bucaramanga es un tema que actualmente se encuentra en estado rudimentario debido al desconocimiento o a la inadecuada implementación de condiciones para alcanzar tal fin. Pese a ello, desde la academia se viene promoviendo la responsabilidad social de la arquitectura y el urbanismo, con el objetivo de diagnosticar y proponer soluciones de accesibilidad universal que permitan valorar el estado actual del equipamiento urbano para lograr su mejoramiento. Como muestra de lo anterior, el presente artículo, producto de una actividad académica de maestría elaborada por el autor, pretende abordar, mediante una metodología con enfoque cualitativo de la investigación, el estudio de caso sobre el "Parque de los Niños" de esta ciudad a partir de un proceso descriptivo de la información. Los criterios asignados para la obtención del diagnóstico se centran en la valoración de accesos, itinerarios, cambios de nivel, zonas de juego, mobiliario urbano y señalización. Por su parte, para las consideraciones a tener en cuenta en las soluciones propositivas se han planteado mejoras en los accesos y la movilidad peatonal, en las zonas de juegos, en el mobiliario urbano y la señalización que puedan garantizar la consecución de un entorno urbano incluyente para todos.

\section{PALABRAS CLAVE}

Accesibilidad universal, diseño para todos, espacio público, Parque de los Niños, inclusión social. 


\section{DIAGNOSIS AND PROPOSALS FOR DEVELOPING UNIVERSAL ACCESSIBILITY AND DESIGN-FOR-ALL IN PARQUE DE LOS NIÑOS OF BUCARAMANGA}

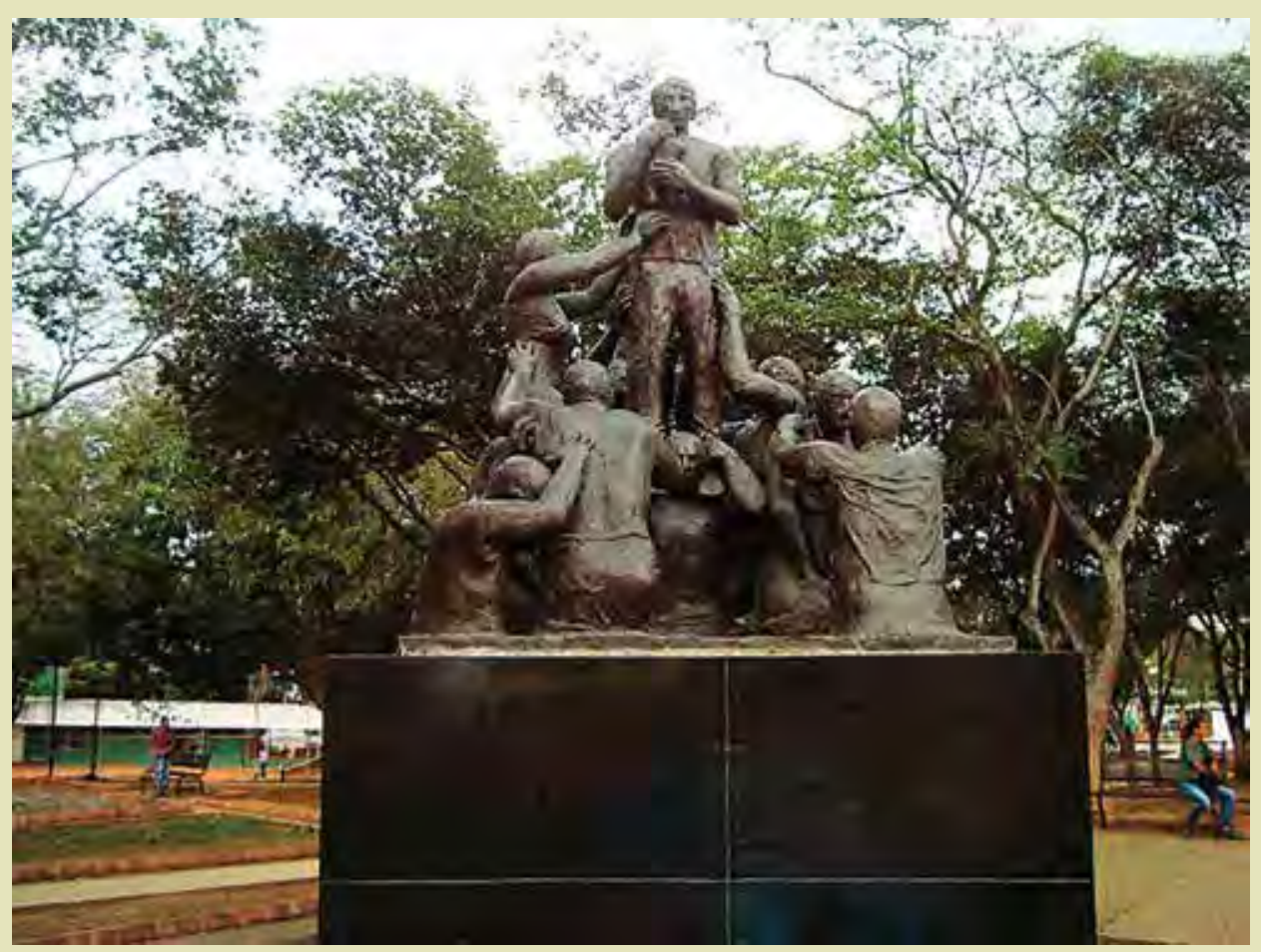

Monumento "Los 19 comerciantes" en el Parque de los Niños, Bucaramanga. Fuente: Leonardo Enrique Díaz Suárez, 2015.

\begin{abstract}
The pursuit of equal opportunities for the public space of Bucaramanga is an issue that currently is currently in a very poor state due to ignorance or an inappropriate implementation of conditions to achieve this goal. Despite this, the academy has been promoting the social responsibility of architecture and urbanism, with the aim of diagnosing and proposing solutions linked to universal accessibility that allow to assess urban facilities current state in order to improve them. As prove of the above description, this article, product of an academic master's activity developed by the author, tries to approach through a methodology with a research qualitative approach to the study case of "Parque de los Niños" in this city, beginning with a descriptive process of the information. The criteria used to obtain the diagnosis are focused on the assessment of access, itineraries, level changes, play areas, street furniture and signage. On the other hand, for the considerations to be taken into consideration in further proposals, it has been planned improvements in the access areas and also in the pedestrian mobility, the play areas, the urban furniture and the signaling in order to guarantee the achievement of an inclusive urban environment for all.
\end{abstract}

\section{KEYWORDS}

Universal accessibility, design for all, public space, Parque de los Niños, social inclusion. 


\section{INTRODUCCIÓN}

Las disposiciones para el pleno ejercicio de las personas con discapacidad en Colombia, según la Ley estatutaria 1618 de 2013, tienen como objeto garantizar y asegurar el ejercicio efectivo de sus derechos mediante la adopción de medidas de inclusión, acción afirmativa y de ajustes razonables y eliminando toda forma de discriminación. A su vez, en el título II sobre definiciones y principios, define la accesibilidad como:

Condiciones y medidas pertinentes que deben cumplir las instalaciones y los servicios de información para adaptar el entorno, productos y servicios, así como los objetos, herramientas y utensilios, con el fin de asegurar el acceso de las personas con discapacidad, en igualdad de condiciones, al entorno físico, el transporte, la información y las comunicaciones, incluidos los sistemas y las tecnologías de la información y las comunicaciones, tanto en zonas urbanas como rurales [...]. (p.l)

Con base en estos argumentos, se hace necesaria la valoración de los niveles de acceso que presentan nuestras ciudades, tanto en las edificaciones de uso público, privado o residencial, como en el espacio público y los modos o medios de transporte que las integra, para entender de manera oportuna cuáles han de ser los criterios y parámetros más apropiados para devolverle a todos sus habitantes el territorio que, desde hace décadas, ha venido perdiendo el enfoque humano, el cual se ha colmado de espacios con obstáculos arquitectónicos, actitudinales y de movilidad que poco o nada contribuyen a la inclusión social e igualdad de oportunidades que se requieren para el sano desarrollo y mejoramiento de nuestra sociedad.

Frente a ello, en el presente trabajo se desarrolla la ejecución de un diagnóstico con propuestas de accesibilidad en un espacio urbano ubicado en la ciudad de Bucaramanga, Colombia. Esto se realiza como ejercicio académico a partir del módulo presencial realizado por el autor en el año 2015, para optar por el título de "Máster en Accesibilidad para Smart City; La Ciudad Global", llevado a cabo por la Universidad de Jaén en España, dentro de las actividades programadas en la Semana de la Accesibilidad de Madrid, (MAW) 2015.

El lugar analizado corresponde al llamado "Parque de las Niños", un espacio de integración y participación muy tradicional en esta capital, enmarcado entre las calles 30 y 32 y las carreras 26 y 27 , siendo esta última, una de las principales arterias vehiculares de la ciudad. A su vez, el parque está implantado en medio de una importante zona de equipamiento urbano, como se puede observar en la Figura I, la cual está compuesta por el Instituto Municipal de Cultura y Turismo (IMCT) junto con la biblioteca pública Gabriel Turbay y el auditorio Pedro Gómez Valderrama, la Clínica los Comuneros (CC), la Universidad Antonio Nariño (UAN), la Escuela Normal Superior de Bucaramanga (ENSB), la Escuela Anexa Club de Leones (EACL) y la Parroquia de Nuestra Señora de Fátima (PNSF).

De igual manera, el parque se compone de diferentes zonas para la realización de diversas actividades de deporte y esparcimiento, tales como: canchas de tenis (CT), canchas múltiples (CM) para baloncesto, microfútbol u otros deportes y un parque didáctico (PD) para enseñar a los niños acerca de movilidad y cultura ciudadana en el transporte. Además de esto, al interior del lugar se encuentran una serie de senderos peatonales, plazoletas, ciclo ruta, estancias, esculturas, zonas verdes y parqueaderos en el perímetro. Todo esto para responder a las necesidades de espacio público que requieren los desarrollos de vivienda unifamiliar y multifamiliar en altura existentes en el sector y para los visitantes de constante concurrencia que a diario acuden o transitan por allí. 
La estructura argumentativa está basada en un estudio por fases del sector analizado, con el fin de comprender las particularidades y los componentes que conforman el parque, para establecer las relaciones entre estos y con el equipamiento urbano que integran, lo cual ha de permitir la configuración del diagnóstico general del entorno, conducente a la generación de propuestas basadas en las normas sobre accesibilidad universal más actualizada en Colombia, tales como: Fique (2000), Instituto Colombiano del Deporte, Comité Paralímpico Colombiano, Asociación Colombiana de Universidades, Federación Colombiana de Organizaciones de Personas con Discapacidad Física (2009), Instituto Colombiano de Normas Técnicas y Certificación (2013) y la Norma Técnica Colombiana NTC 6047 (2013).

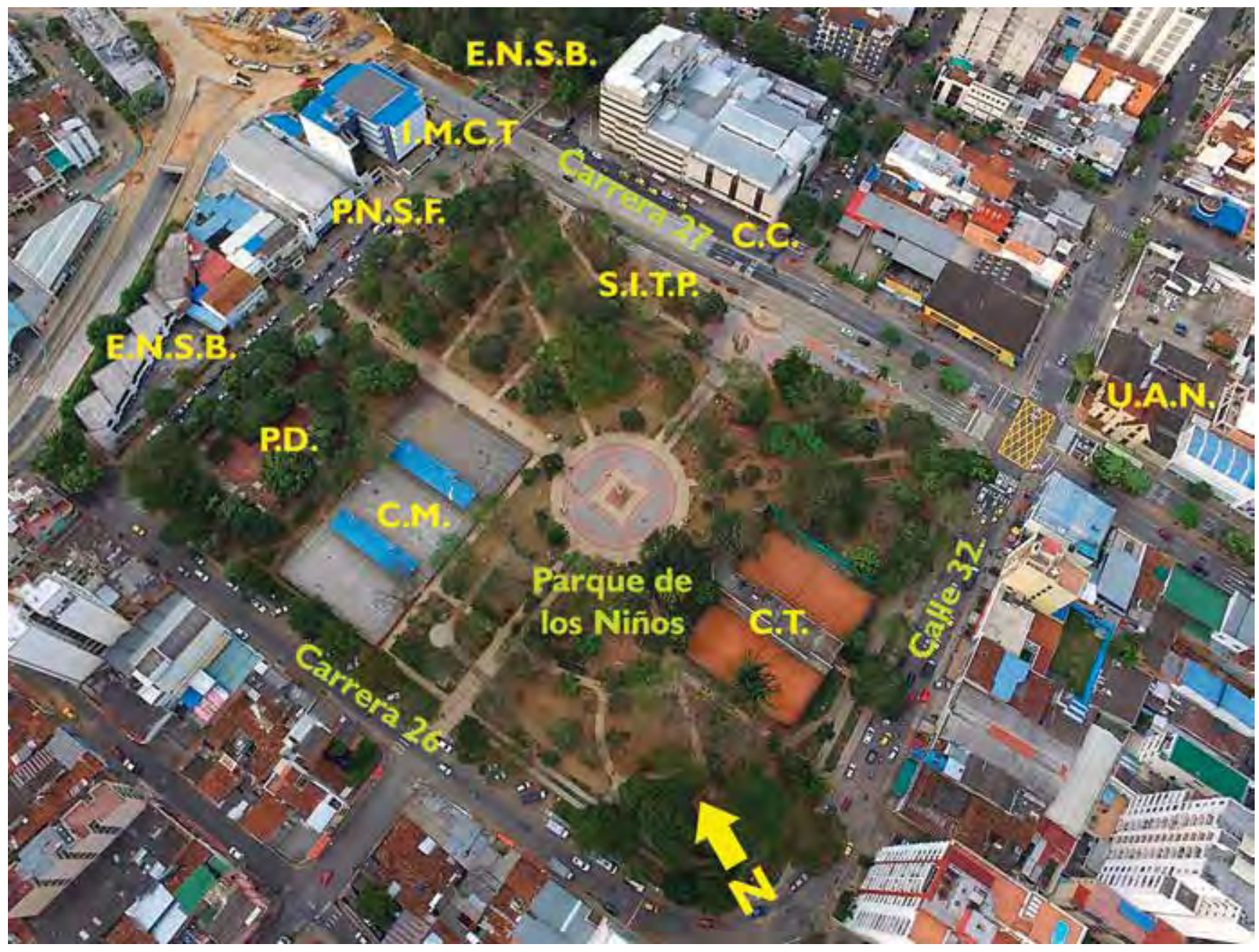

\section{METODOLOGÍA}

En el desarrollo del estudio de caso sobre el diagnóstico y propuestas de accesibilidad para el Parque de los Niños, se tuvo en cuenta un proceso descriptivo de la información aplicado al enfoque cualitativo que ha pretendido alcanzar la mayor comprensión del entorno y su problemática para poder formular los resultados mediante 3 fases: de recopilación de la información, fase de valoración y fase propositiva.

Para la fase de recopilación de la información, se acudió al parque con el fin de valorar las condiciones de accesibilidad que posee en la actualidad, haciendo un recorrido completo del mismo. Al mismo tiempo, se efectuó un inventario fotográfico de cada uno de los aspectos a tener en cuenta para el diagnóstico y propuestas de la intervención.
Figura I. Ubicación del equipamiento urbano existente en el Parque de los Niños.

Fuente: Alberto Felipe Rodríguez Sanabria, 2015. 
Como indicadores de la actividad, se encontró como común denominador de percepción un estado de deterioro físico debido a la falta de aseo y mantenimiento que se hace bastante evidente (Figuras 2, 3), pese a que en el año 2007 se ejecutó una remodelación general de todas las instalaciones por parte de la Gobernación de Santander (Figura 4) y actualmente se adelantan otras adecuaciones en el sector sur-occidental, aisladas con malla de cerramiento (Figura 5).

Por otra parte, la ausencia de buenas prácticas en los ámbitos de la accesibilidad se presenta en todos los sectores que conforman el parque, ocasionando que los visitantes de todas las edades y deportistas con discapacidad (Figuras 6,7) que acuden, se vean enfrentados a una cadena de obstáculos arquitectónicos que ameritan una solución pertinente, la cual no se efectuó desde el mismo momento en el que se configuró el ejercicio proyectual de la remodelación.

Espacios como el parque didáctico para niños, que se supone son los que dan significado al nombre del lugar, poseen inconsistencias desde el punto de vista de la pedagogía infantil relacionada con la accesibilidad y la cultura ciudadana, presentando una recreación excluyente del espacio público: transporte y segregación mediante el uso de mallas eslabonadas (Figuras $10, \mathrm{I}$ ) que no contribuyen a la percepción de lo público ni a la idea de inclusión social de una capital reconocida a nivel nacional como "La ciudad de los parques".

Para la fase de valoración de la accesibilidad en el parque, se tuvieron en cuenta los siguientes criterios como ítems para el análisis del estado actual de este: accesos, itinerarios, cambios de nivel, zonas de juego, mobiliario urbano y señalización. Como resultado, se ha deducido la necesidad recuperar un sector tan significativo para Bucaramanga que reivindique la imagen de la ciudad y dignifique la posición de prioridad que ocupa la infancia en la sociedad, además de incluir a las personas con diversidad funcional y población vulnerable.

En la fase propositiva se han concretado todas las consideraciones a tener en cuenta en el estudio, basadas en la normativa sobre accesibilidad universal vigente en Colombia, con el propósito de definir cuáles son las intervenciones que requiere el parque para que pueda ser aceptado como un espacio público accesible e incluyente, mediante el planteamiento de adecuaciones $y$ adaptaciones que garanticen el derecho a un equipamiento urbano de calidad, el cual simbolice y haga tangible la igualdad de oportunidades para toda la ciudadanía.

\section{DIAGNÓSTICO}

\section{Accesos}

La principal vía de acceso al sitio es la carrera 27, donde se encuentra la estación del Sistema Integrado de Transporte Público de Bucaramanga (Figuras 12, 13). Dicha ruta está reducida temporalmente a un solo carril debido a las obras que se adelantan para la construcción de un intercambiador unos metros antes de llegar al parque en sentido nortesur. Es evidente la inadecuada implementación del encaminamiento podotáctil, guía para personas con discapacidad visual, el cual no conduce a la entrada de la estación, sumado al hecho de tener árboles implantados justo frente a las entradas de la misma y ausencia total de señalización exterior que advierta sobre la existencia de la parada o de las rutas del sistema al interior. Las compuertas acristaladas para acceder al autobús no poseen ningún tipo de señalización $y$, al interior, no existen bancas ni apoyos isquiáticos para personas con movilidad reducida. No existe una franja de contraste cromático entre acera y calzada que alerte sobre el cambio de nivel a personas con discapacidad visual. 


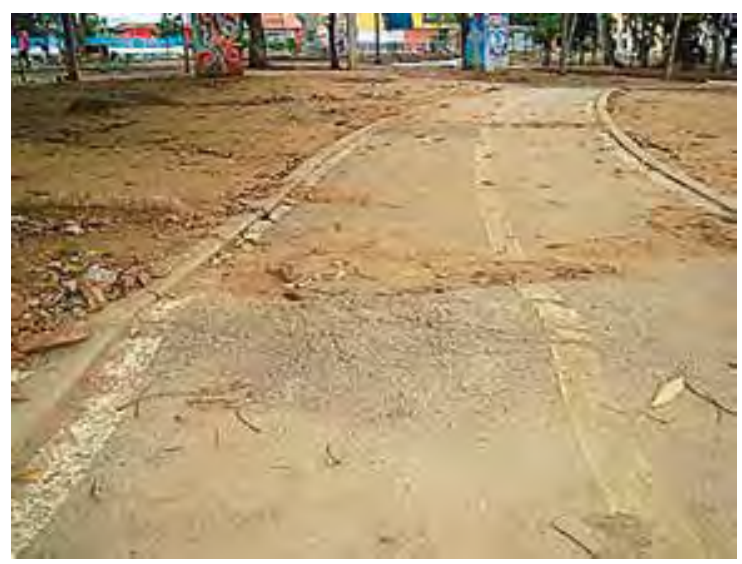

Figura 2. Deterioro de la cicloruta

Fuente: Leonardo Enrique Díaz Suárez, 2015.

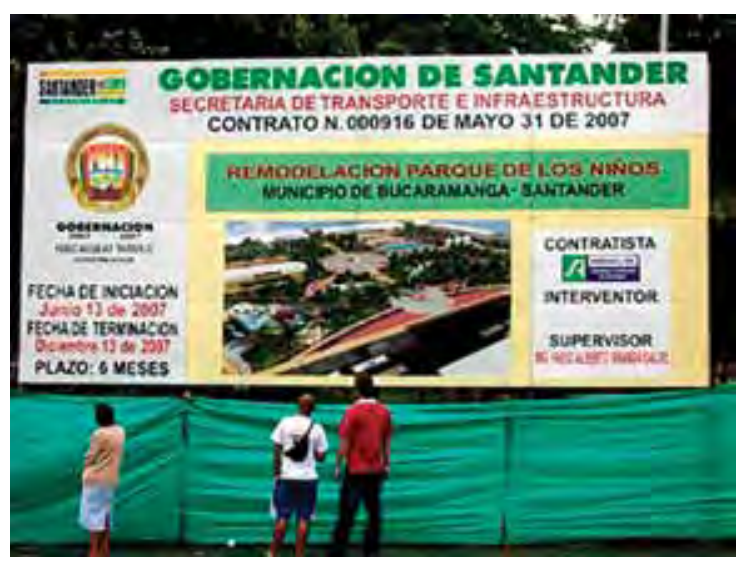

Figura 4. Remodelación Parque de los Niños.

Fuente: Tomado de Reyes (2009, p.78).

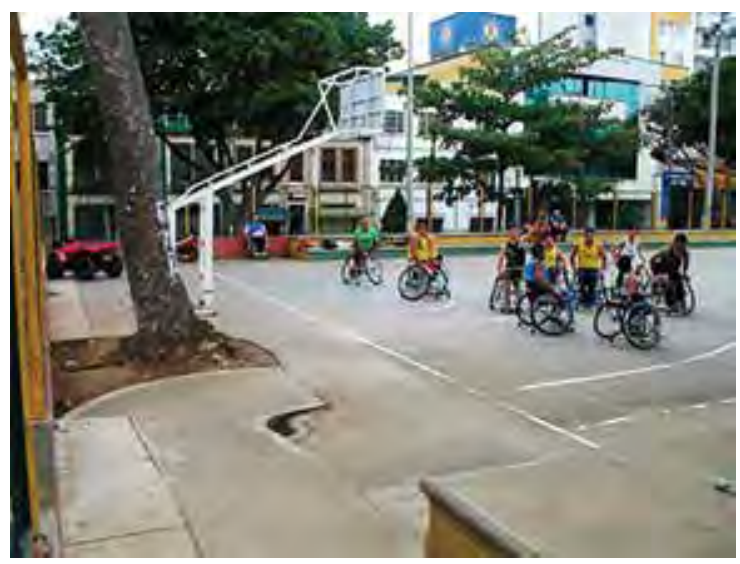

Figura 6. Acceso cancha múltiple.

Fuente: Leonardo Enrique Díaz Suárez, 2015.

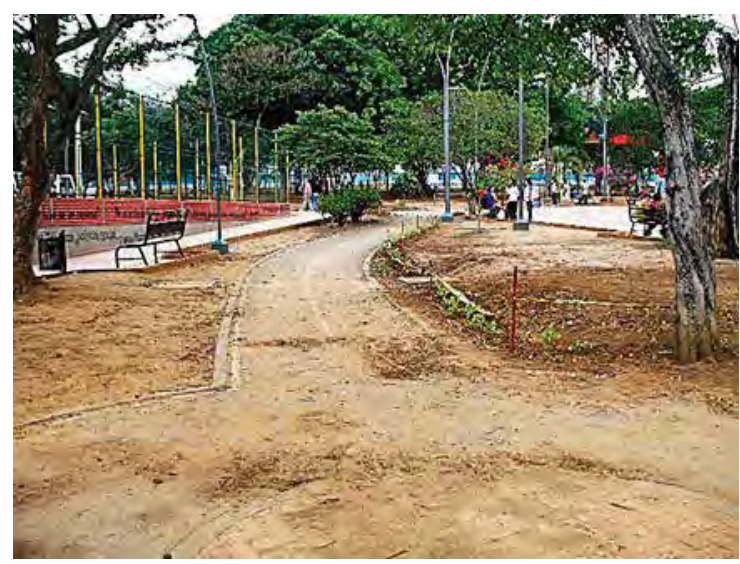

Figura 3. Falta de mantenimiento. Fuente: Leonardo Enrique Díaz Suárez, 2015

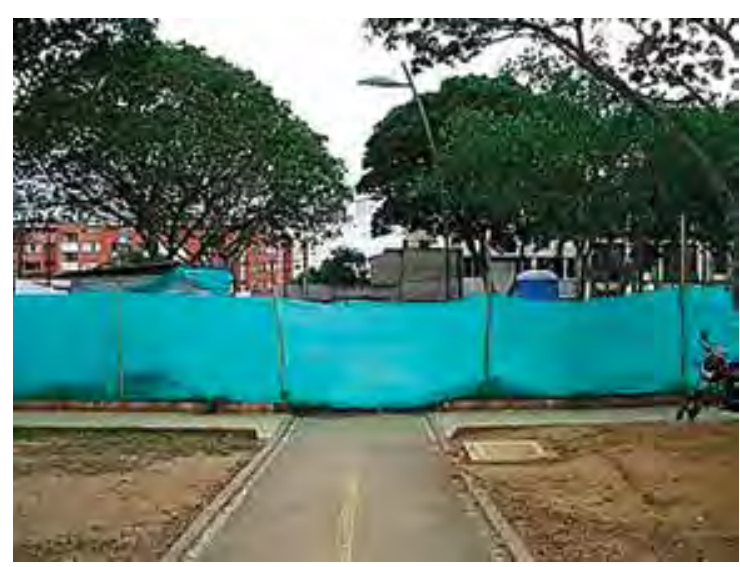

Figura 5. Adecuaciones sector sur-occidental. Fuente: Leonardo Enrique Díaz Suárez, 2015.

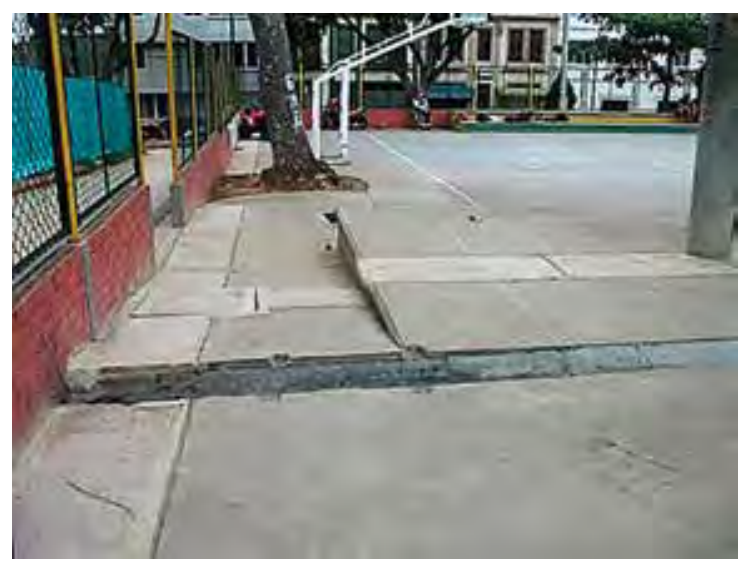

Figura 7. Canal de aguas lluvias. Fuente: Leonardo Enrique Díaz Suárez, 2015 


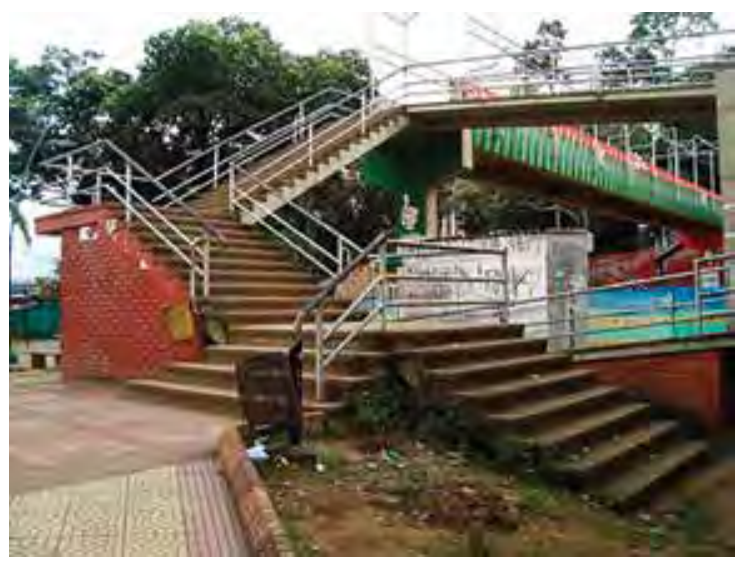

Figura 8. Acceso puente peatonal.

Fuente: Leonardo Enrique Díaz Suárez, 2015.

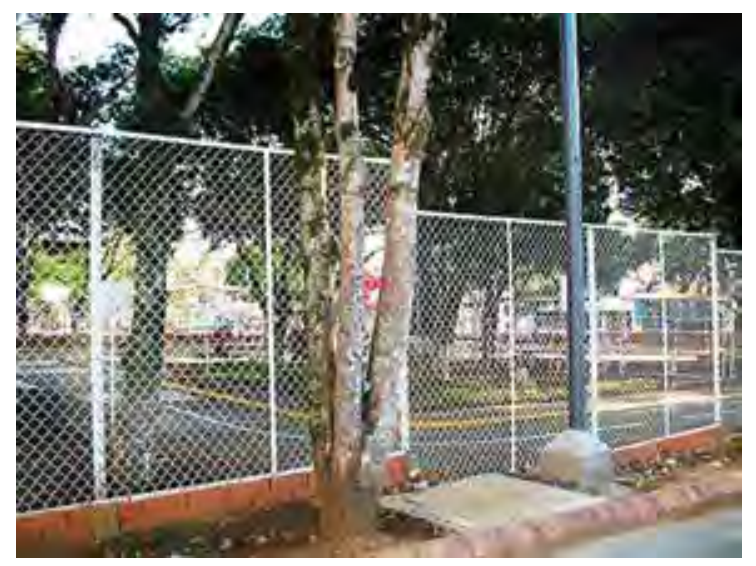

Figura 10. Cerramiento parque didáctico.

Fuente: Leonardo Enrique Díaz Suárez, 2015.

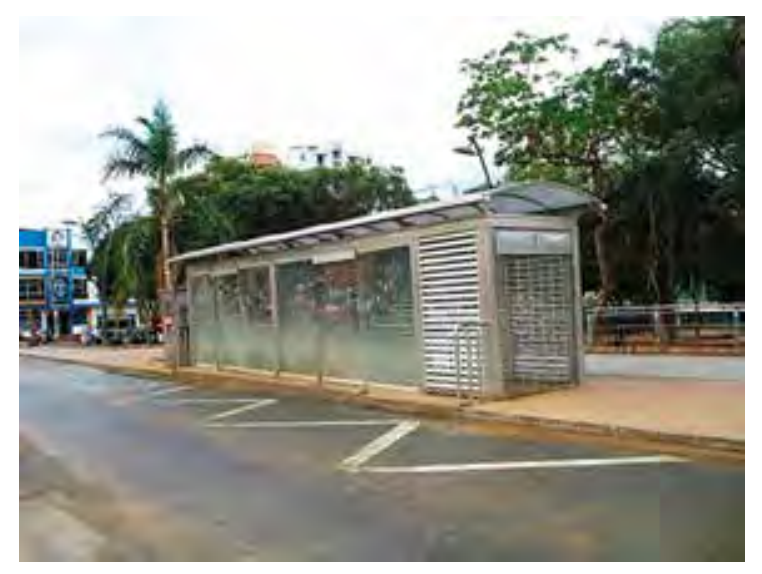

Figura 12. Estación SITP.

Fuente: Leonardo Enrique Díaz Suárez, 2015.

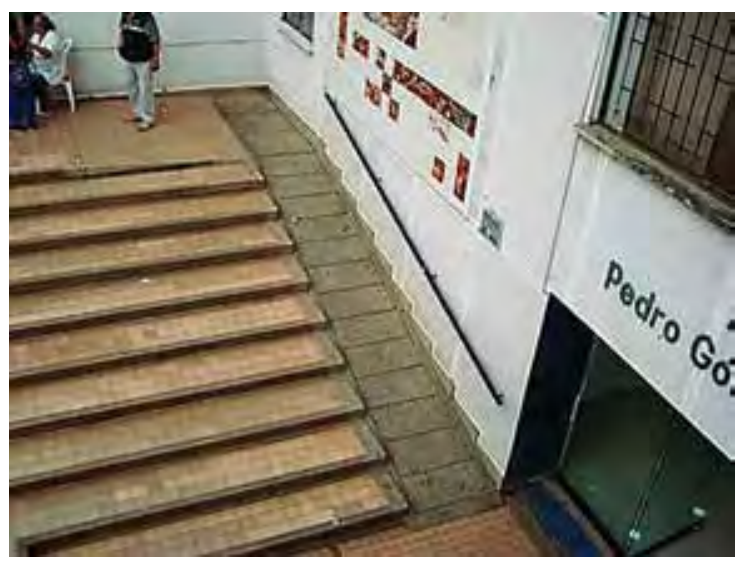

Figura 9. Acceso auditorio del IMCT. Fuente: Leonardo Enrique Díaz Suárez, 2015.

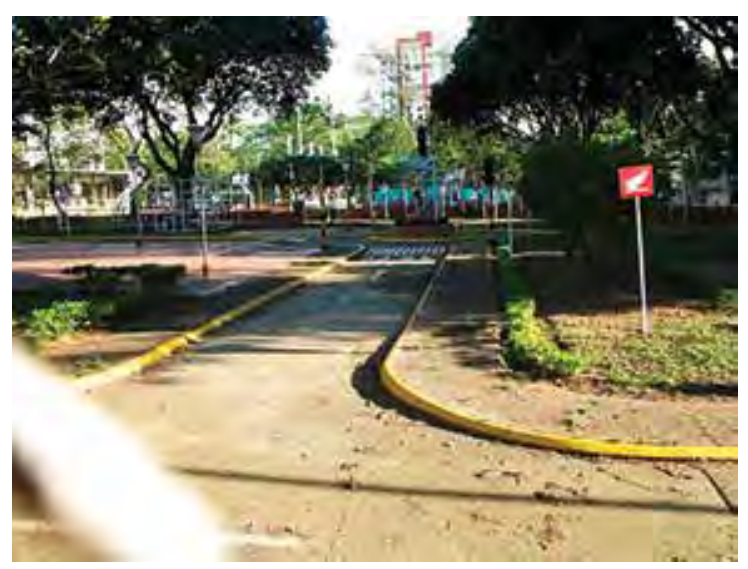

Figura II. Interior parque didáctico. Fuente: Leonardo Enrique Díaz Suárez, 2015.

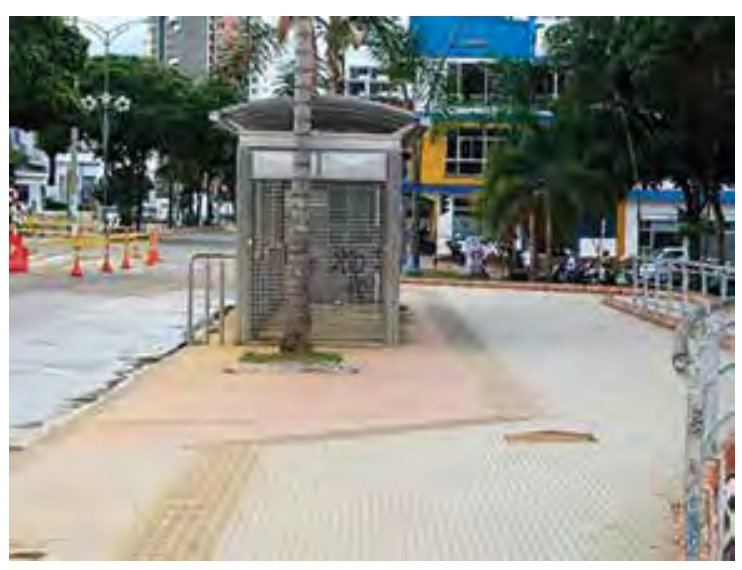

Figura I3. Acceso estación SITP. Fuente: Leonardo Enrique Díaz Suárez, 2015. 
El acceso peatonal por la plazoleta de la carrera 27 (Figura 14) presenta deterioro, mientras que el puente peatonal (Figura 15) que integra el parque con la Escuela Normal Superior de Bucaramanga no cumple con los criterios de accesibilidad establecidos por norma. En general, se observan escalones sin pasamanos intermedios o solo a un costado del tramo, con boceles partidos (que no deberían haberse hecho) y los pasamanos no poseen doble altura, además de tener tramos sin continuidad y ausencia de información en braille. No poseen bordillos guía; no hay contraste cromático en las huellas; tampoco franjas de señalización podotáctil de advertencia para el cambio de nivel; ni descansos intermedios en la rampa. Las pendientes no son las apropiadas para la deambulación en silla de ruedas.

En los accesos al Instituto Municipal de Cultura y Turismo, que se integra al flujo del puente peatonal (Figuras 16, 17), los parámetros para escaleras y rampas no se implementaron adecuadamente, especialmente en la adaptación de pasamanos, pendientes, bordillos, descansos, contraste cromático y losetas podotáctiles, al comienzo y al final de las circulaciones verticales.

La entrada al parque didáctico no posee obstáculos arquitectónicos (Figura 18), mientras que el acceso a las canchas de tenis muestra un inadecuado uso de las losetas podotáctiles desde su inicio en el vado peatonal (Figura 19), el cual tampoco se enrasó correctamente con el nivel de la calzada, ni se demarcó con contraste cromático para advertir el cambio de nivel.

El acceso adaptado personas con discapacidad por el costado de la calle 30 (Figura 20) se reduce a un pequeño vado de ancho no apropiado, teniendo en cuenta las dimensiones del itinerario peatonal con el que comunica, lo que permite que los vehículos se parqueen junto a él, obstruyendo aún más el espacio de circulación. Por otra parte, la entrada por la carrera 26 (Figura 2I), que conduce a las canchas múltiples, presenta un ancho adecuado del itinerario, pero presenta el mismo problema de invasión vehicular al inicio de este y falta de mantenimiento.

Las zonas de estacionamiento vehicular (Figuras 22, 23) evidencian desorganización permanente debido a la ausencia total de demarcación. No hay plazas de parqueo para personas con discapacidad por ninguna de las vías de acceso que rodean el parque.

\section{Itinerarios}

Las aceras peatonales en su mayoría no cuentan con encaminamientos podotáctiles, pero hay bordillos guía instalados para facilitar la orientación de personas con discapacidad visual. Tampoco hay franjas de contraste cromático que adviertan el cambio de nivel entre andén y calzada (Figura 24). A su vez, en los itinerarios, donde se instalaron losetas podotáctiles (Figura 25), no fue realizado de modo adecuado; observándose discontinuidad e inapropiada implementación de la función que desempeña cada tipo de loseta en relación con el flujo peatonal y la interacción con el vado peatonal.

\section{CAMBIOS DE NIVEL}

Las escaleras (Figuras 26, 27) no cuentan con pasamanos a doble altura intermedios o en los costados. No hay franjas de señalización podotáctil, en la mayoría de ellas, para advertir el cambio de nivel al comienzo y al final del tramo y en los pocos casos donde se instaló, se hizo de modo erróneo. No se incorporó el contraste visual en las huellas y la franja cromática entre andén y calzada no es continua. Los pasamanos no cuentan con información en braille. 


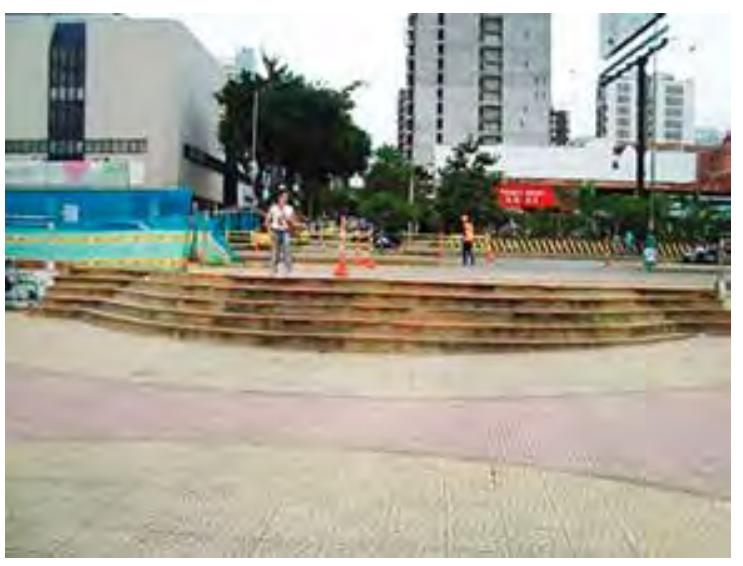

Figura I4. Acceso carrera 27.

Fuente: Leonardo Enrique Díaz Suárez, 2015.

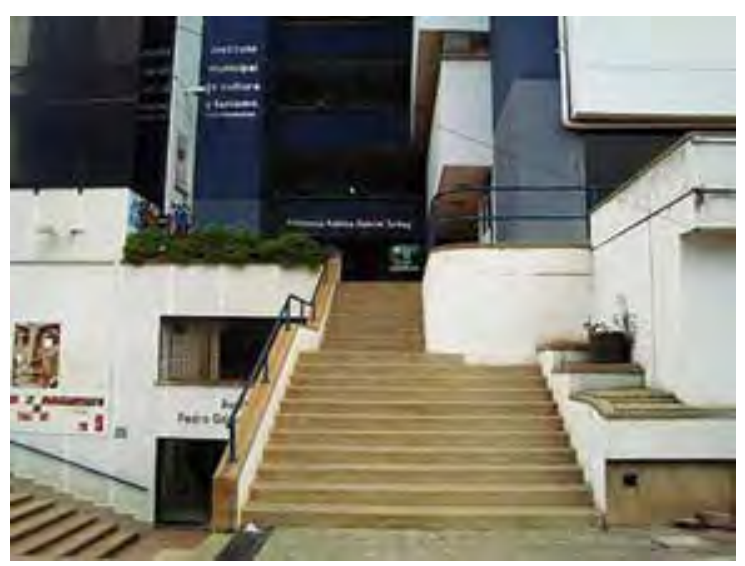

Figura 16. Acceso principal IMCT.

Fuente: Leonardo Enrique Díaz Suárez, 2015.

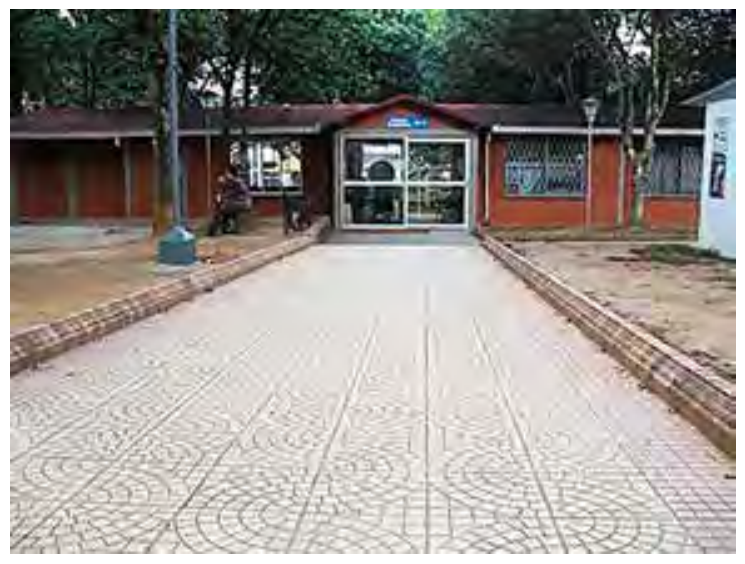

Figura 18. Acceso parque didáctico.

Fuente: Leonardo Enrique Díaz Suárez, 2015.

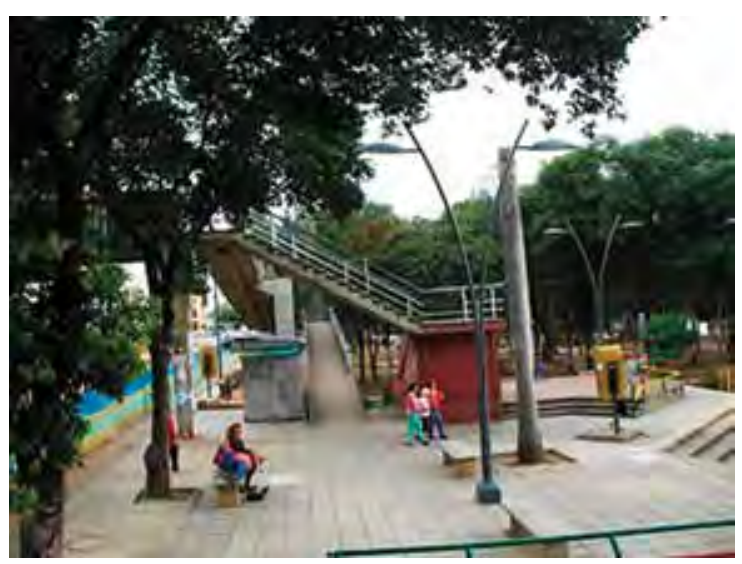

Figura I5. Puente peatonal y circulaciones. Fuente: Leonardo Enrique Díaz Suárez, 2015.

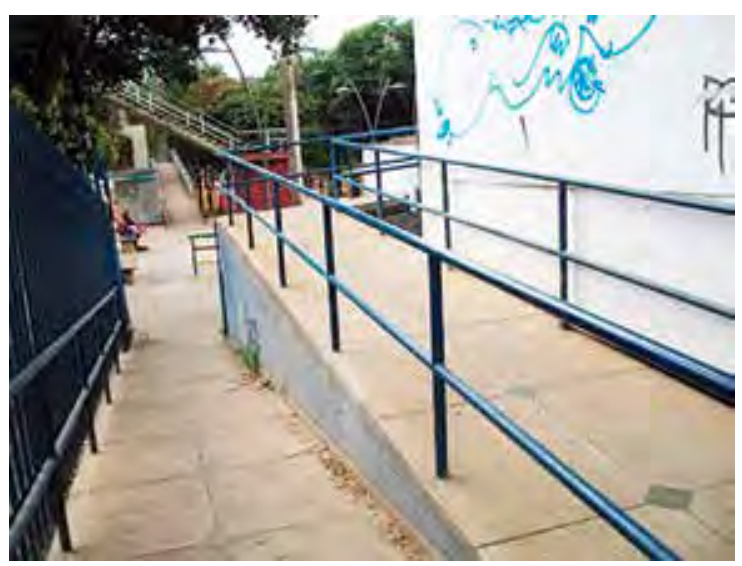

Figura 17. Rampa de acceso IMCT. Fuente: Leonardo Enrique Díaz Suárez, 2015.

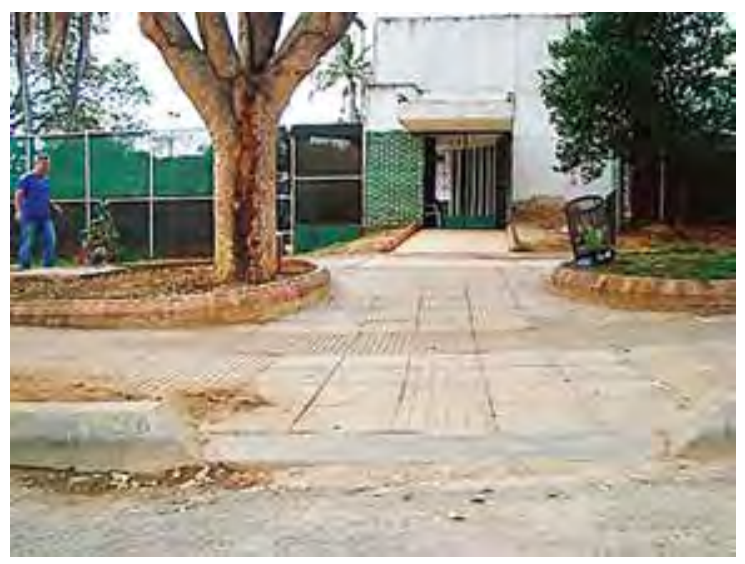

Figura 19. Acceso canchas de tenis. Fuente: Leonardo Enrique Díaz Suárez, 2015. 


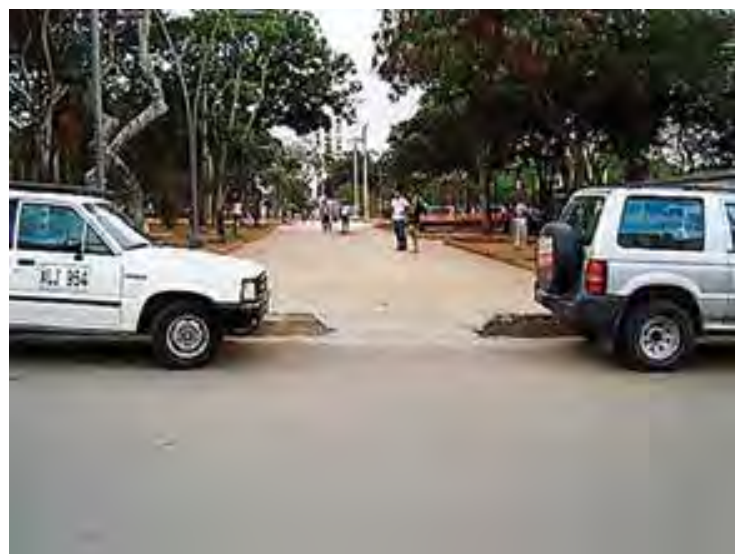

Figura 20. Acceso calle 30

Fuente: Leonardo Enrique Díaz Suárez, 2015.

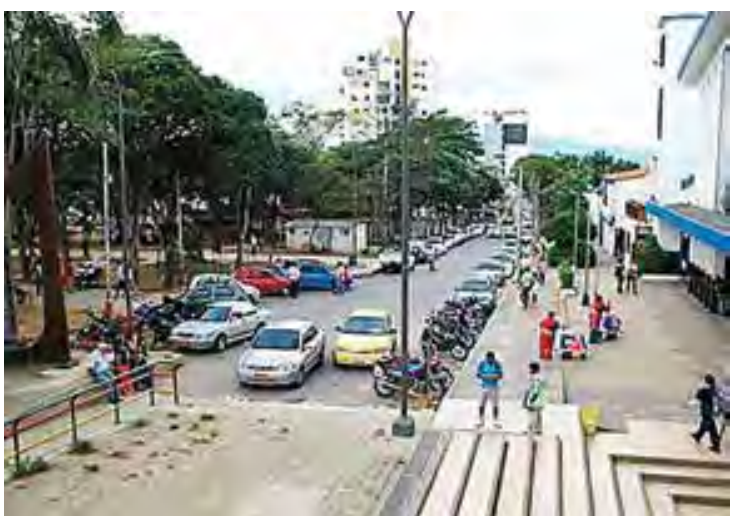

Figura 22. Parqueaderos calle 30

Fuente: Leonardo Enrique Díaz Suárez, 2015.

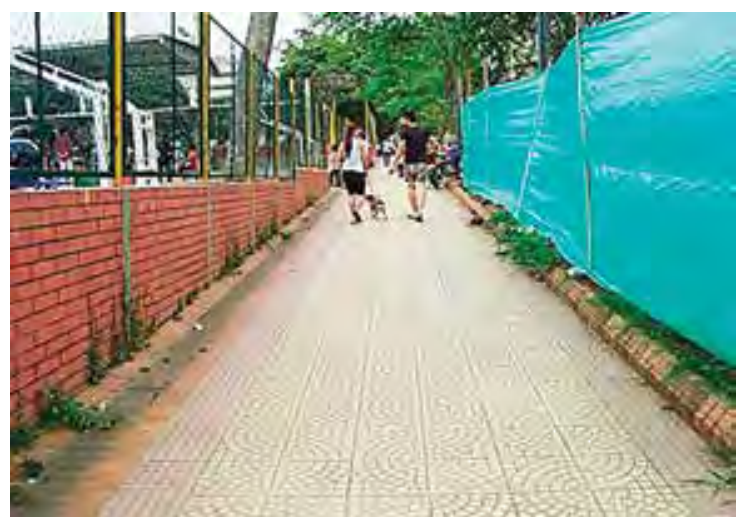

Figura 21. Acceso carrera 26 Fuente: Leonardo Enrique Díaz Suárez, 2015.

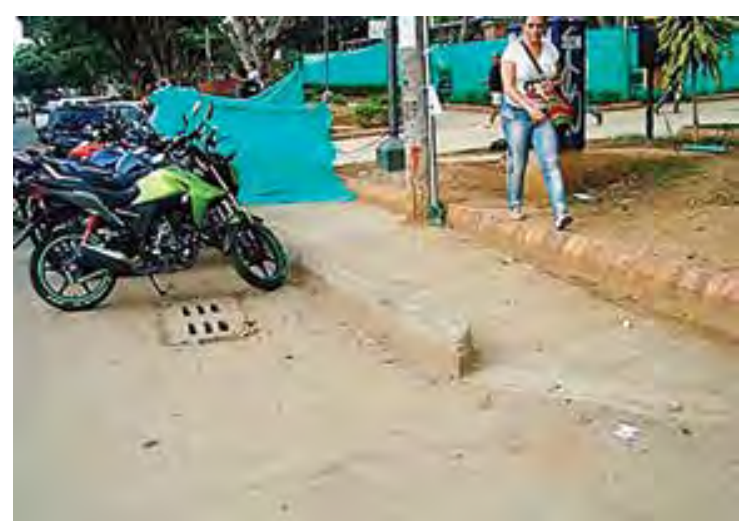

Figura 23. Parqueaderos carrera 26. Fuente: Leonardo Enrique Díaz Suárez, 2015.

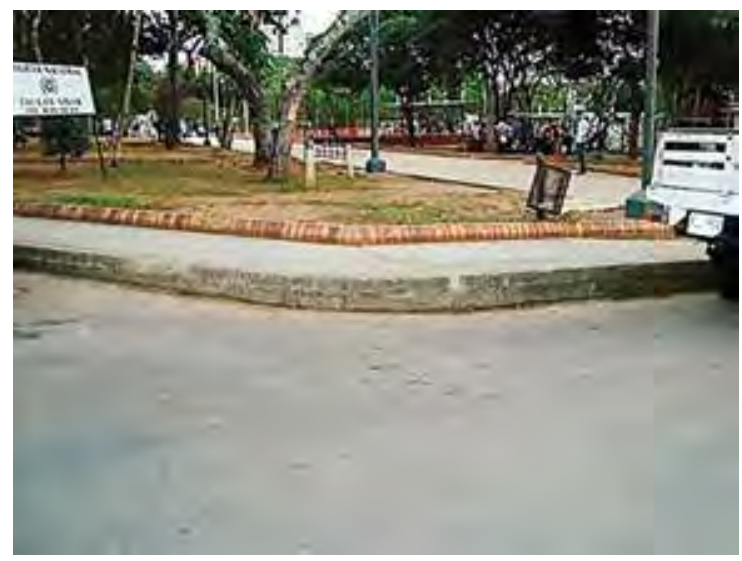

Figura 24. Andén calle 30.

Fuente: Leonardo Enrique Díaz Suárez, 2015. 
Figura 25. Losetas podotáctiles calle 32. Fuente: Leonardo Enrique Díaz Suárez, 2015.

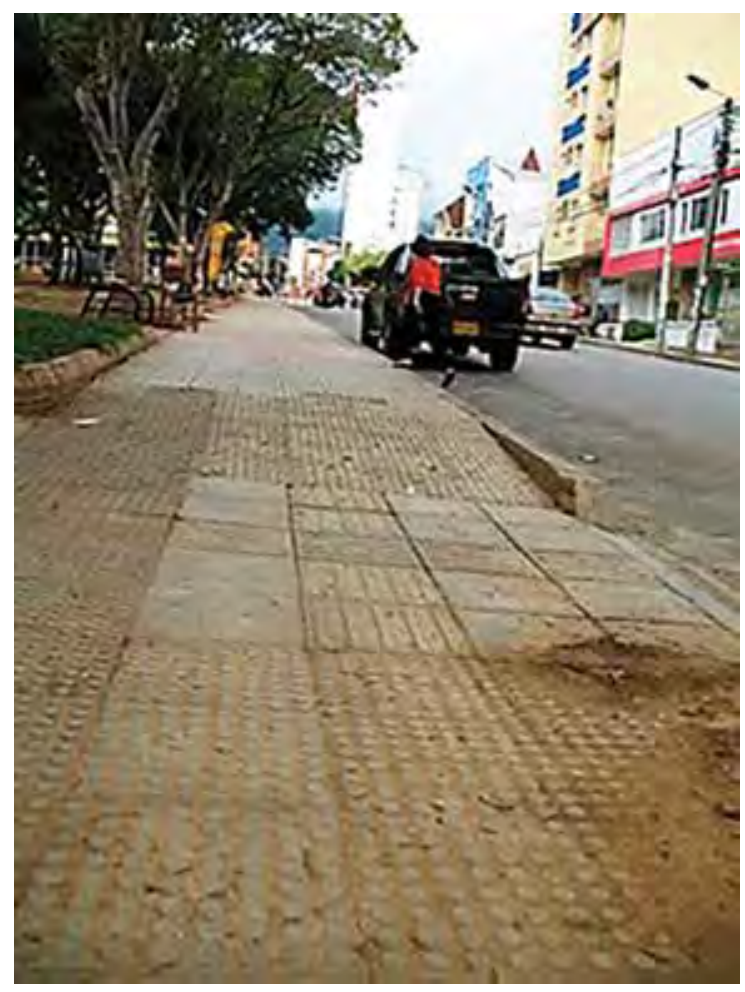

Las rampas (Figura 27) presentan problemas similares, presentando pasamanos y barandillas sin criterios accesibles, con aristas vivas, instalados a un solo lado del tramo y sin bordillos. Además, se puede apreciar la instalación de encaminamientos podotáctiles guía a lo largo del plano inclinado, donde no deberían estar, omitiendo la implementación de advertencia al comienzo y al final del tramo para señalizar el cambio de nivel.

\section{Zonas de juego}

Si bien una de las canchas múltiples permite el acceso a personas usuarias de sillas de ruedas, la adecuación del plano inclinado en la entrada no tiene una solución normativa, al presentar un giro curvo sin descanso ni protección con bordillos guía, sumado al hecho de no haber instalado franjas podotáctiles de advertencia. En la Figura 7 se puede apreciar que existe un canal de aguas lluvias sin rejilla que impide la circulación hacia las demás canchas que se visualizan en el fondo de la Figura 28. En cuanto a las canchas de tenis, por su necesario cerramiento enmallado (Figura 29), se transmite la connotación simbólica de segregación social frente a los demás servicios públicos que ofrece el lugar.

Paradójicamente, el "Parque de los Niños" no cuenta con una zona pública de juegos infantiles como tal, siendo el parque didáctico la única zona destinada para tal fin.

\section{Mobiliario urbano}

Las bancas no obstruyen los itinerarios peatonales. Sin embargo, no poseen apoyabrazos, ni están hechas de un material termoestable que neutralice la temperatura originada por el calor. Las papeleras de aseo tampoco obstruyen los senderos y tienen la altura de boca adecuada, pero presentan deterioro y se aprecia la falta de aseo y cultura ciudadana al no depositar los residuos sólidos como corresponde.

En la Figura 30 se observa la obstrucción en la circulación que genera la mala ubicación del teléfono público y la instalación de barandillas sin parámetros accesibles. Cabe anotar que en todo el parque no se encuentran fuentes de agua ni baterías sanitarias públicas.

\section{Señalización}

Junto a los problemas de señalización anteriormente descritos, es importante mencionar que la cicloruta (Figuras 32, 33), desarrollada al interior del parque, no cuenta con ningún tipo de señalización vertical y la demarcación horizontal en el pavimento ya no resalta el contraste cromático requerido para que puedan funcionar de manera segura los recorridos. Ahora bien, lo que más preocupa de esta situación es que la cicloruta se cruza de 


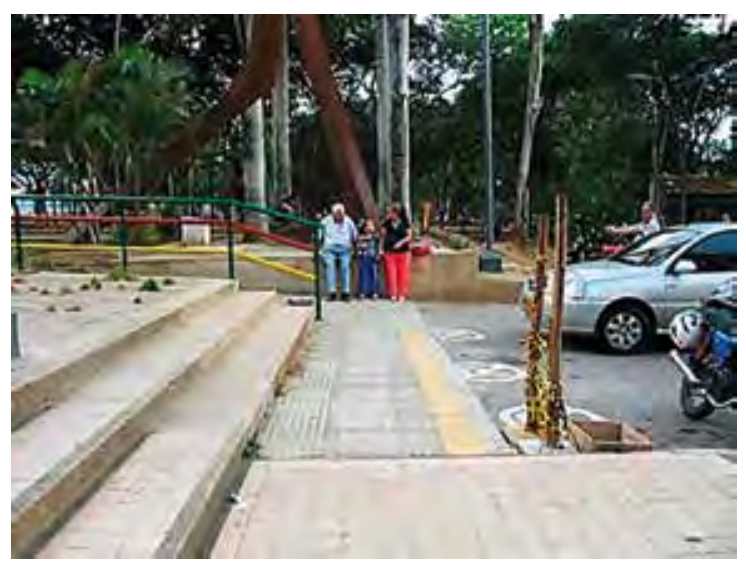

Figura 26. Losetas podotáctiles calle 30.

Fuente: Leonardo Enrique Díaz Suárez, 2015.

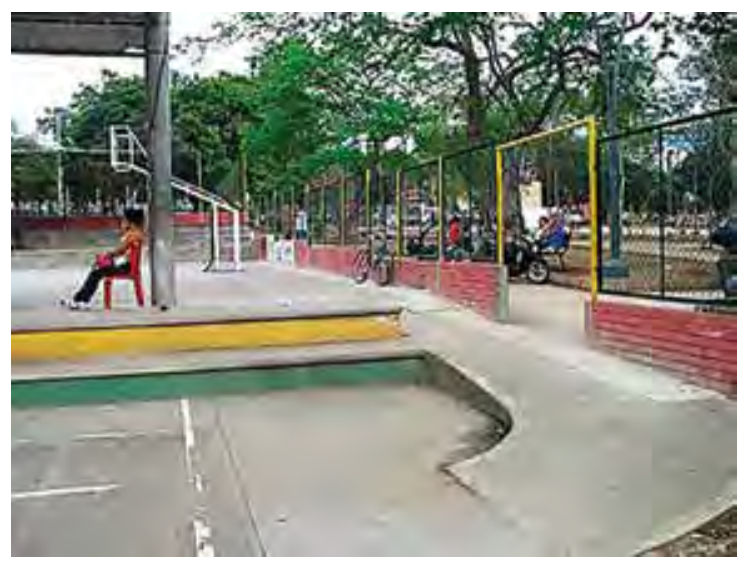

Figura 28. Canchas múltiples.

Fuente: Leonardo Enrique Díaz Suárez, 2015.

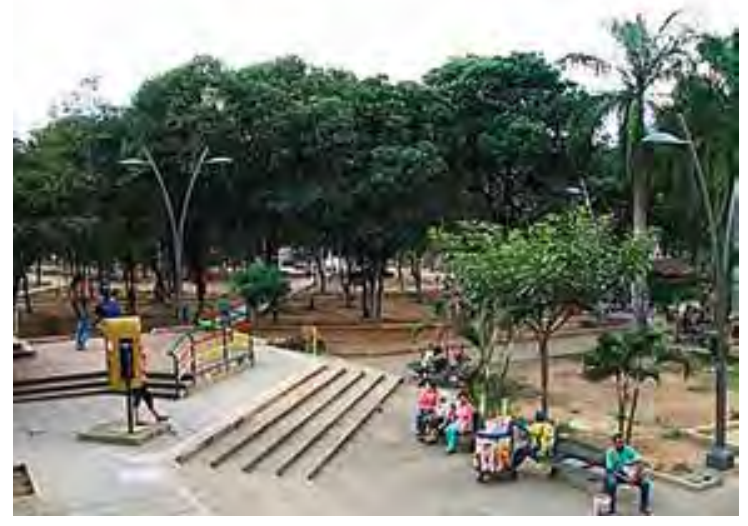

Figura 30. Mobiliario calle 30

Fuente: Leonardo Enrique Díaz Suárez, 2015.

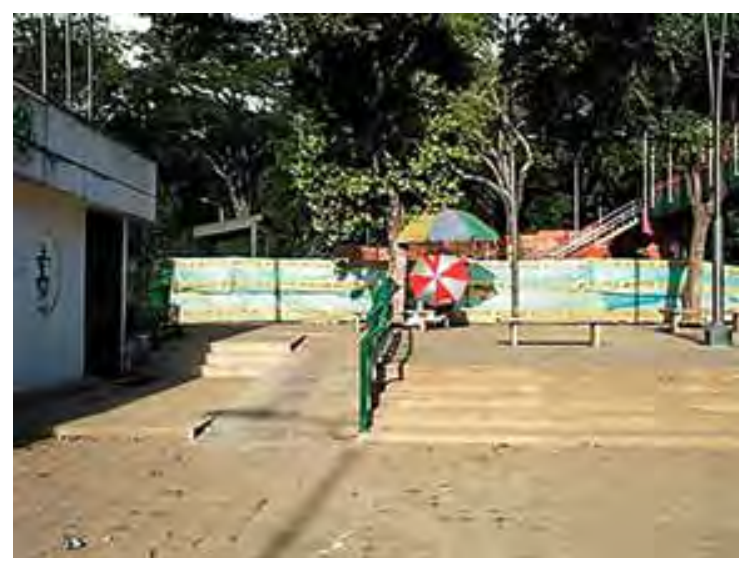

Figura 27. Rampa y escaleras calle 30 Fuente: Leonardo Enrique Díaz Suárez, 2015.

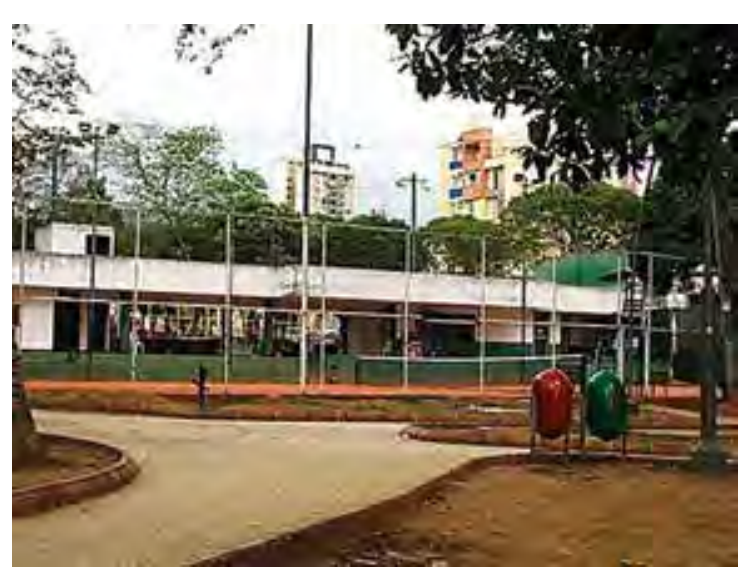

Figura 29. Canchas de tenis. Fuente: Leonardo Enrique Díaz Suárez, 2015.

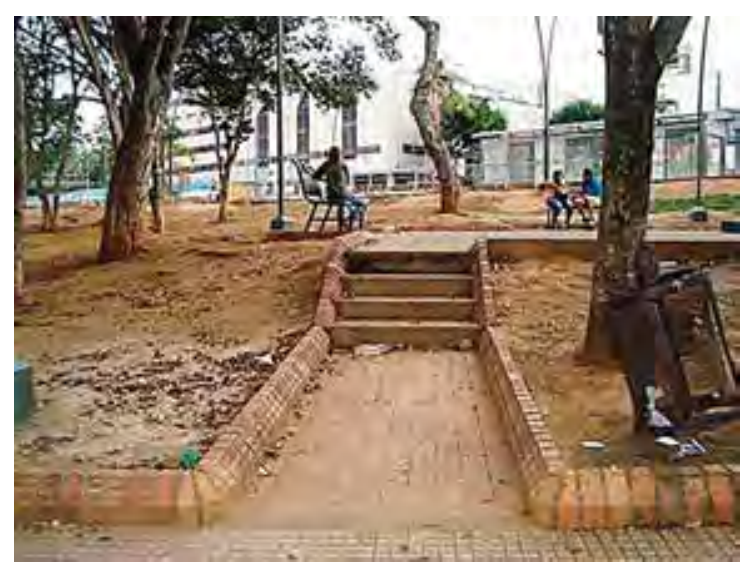

Figura 31. Mobiliario carrera 27. Fuente: Leonardo Enrique Díaz Suárez, 2015. 
Figura 32. Ciclo ruta hacia la calle 32. Fuente: Leonardo Enrique Díaz Suárez, 2015.
Figura 33. Cicloruta hacia la carrera 27. Fuente: Leonardo Enrique Díaz Suárez, 2015.

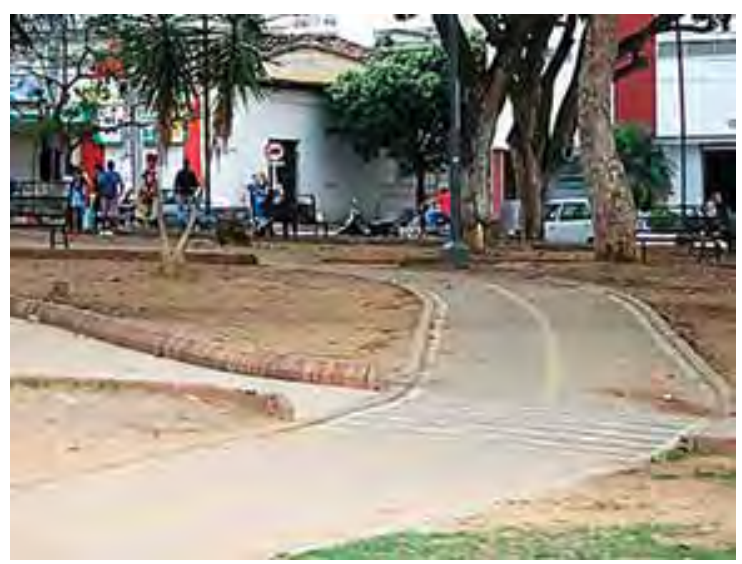

manera frontal con los senderos peatonales en diversos puntos del lugar, sin que existan advertencias visuales $y$ auditivas que alerten sobre el peligro de accidentalidad que pueden generar estos cruces de flujos.

\section{PROPUESTAS}

Resulta bastante pertinente adaptar el concepto y principios del "Diseño para Todos" a un lugar que no fue concebido desde su planteamiento para que garantizase la inclusión de todas las personas al disfrute de un espacio urbano accesible, sin discriminación o segregación social, mediante la implementación de ajustes razonables. Dicho concepto se define como "La intervención sobre entornos, productos y servicios con el fin de que todos, incluidas las generaciones futuras, independientemente de la edad, el sexo, el género, las capacidades o el bagaje cultural, puedan disfrutar participando en la construcción de nuestra sociedad" (IMSERSO. Fundación ONCE. Coordinadora

del diseño para todas las personas en España, 2006, p.30).

Por ello, a continuación, se exponen las consideraciones a tener en cuenta para la mejora de la accesibilidad en el "Parque de los Niños", como soluciones al diagnóstico realizado a partir de los seis criterios analizados para la valoración de este importante sector de la ciudad.

\section{Mejora de los accesos y la movilidad peatonal}

Se propone la incorporación de encaminamientos podotáctiles en el desarrollo de los itinerarios peatonales perimetrales que no posean ningún tipo de recurso para la orientación de personas con discapacidad visual en las aceras, junto con la aplicación de correctivos para mejorar la ubicación y funcionamiento de los existentes. La parada de autobús del SITP también debe contar con franjas podotáctiles que conduzcan hasta su ubicación y con una franja transversal guía que conduzca hasta su acceso. Generalizando, los encaminamientos deben integrar la circulación entre la parada de autobús, los cruces peatonales y los cambios de nivel.

Los accesos al equipamiento urbano y el puente peatonal ameritan la adecuación de sus rampas y escaleras, con la aplicación de pendientes normativas, instalación de pasamanos accesibles a doble altura, continuos y a ambos lados de los tramos e intermedios si se requiere, sin aristas vivas, con información en sistema braille, bordillos guía contrastados, 
franjas de contraste cromático en las huellas, sin boceles en escalones y con franjas de señalización podotáctil de advertencia al comienzo y final de sus tramos.

Los senderos peatonales al igual que la ciclo ruta requieren una renovación de sus pavimentos, así como la adecuación de los cambios de nivel conformados por rampas y planos inclinados, para que también cumplan con los criterios de accesibilidad ya descritos. Dichos pavimentos deberán estar hechos de material antideslizante, tanto en seco como en mojado, disponer de uniformidad en su instalación para no causar tropiezos y garantizar la durabilidad para exteriores y tráfico peatonal masivo.

Los parqueaderos deben contar con cupos para personas con discapacidad debidamente demarcados con franjas de señalización laterales y traseras que conduzcan a los vados peatonales para salvar el desnivel entre calzada y acera. Además, es importante demarcar con señalización horizontal y vertical el símbolo internacional de la accesibilidad (SIA).

\section{Mejora de las zonas de juegos}

Es importante devolverle al parque el componente infantil que simboliza su existencia. Por tal razón, se plantea la inclusión de juegos públicos, biosaludables y accesibles para niños y adultos, con pavimento apropiado para la amortiguación de caídas y materiales termoestables.

Para el parque didáctico se sugiere la eliminación de la malla eslabonada que está generando segregación y rehabilitar la ruta de juego pedagógico, de modo tal que se incorporen los ámbitos de espacio público accesible y señalización, adecuados al sistema de juego ejemplarizante que en algún momento se pretendió proyectar para el fomento de la cultura ciudadana a temprana edad.

Las canchas múltiples deben adaptar sus ingresos para que puedan deambular las personas con discapacidad, sin que encuentren obstáculos que les impidan el desplazamiento a las demás canchas que están integradas. Es necesario acondicionar el plano inclinado de la Figura 28, eliminando la curva, incorporándole un descanso y colocando bordillos guía contrastados cromáticamente, además de franjas señalizadoras de alerta al comienzo y al final del tramo. El canal de aguas lluvias de la Figura 7 requiere ser cubierto con rejillas cuyos orificios garanticen el paso de una silla de ruedas o el arrastre de un bastón blanco para la persona con discapacidad visual, sin que se produzcan posibles atascamientos o caídas. Las graderías deben estar señalizadas con contraste cromático y con la demarcación de espacios para la ubicación de usuarios en silla de ruedas en lugares seguros y de fácil acceso.

En cuanto a las canchas de tenis, se sugiere un tipo de cerramiento en malla complementado con vegetación, que posea accesos públicos y graderías perimetrales que incluyan espacios reservados para personas con discapacidad señalizados horizontalmente. Todo esto para minimizar la connotación de segregación social y aumentar la capacidad del aforo de pública concurrencia.

\section{Mejora del mobiliario urbano}

Los ajustes razonables para la intervención de los elementos de mobiliario han de enfocarse a la rehabilitación de los existentes y a la instalación de componentes que han estado ausentes en la conformación de este espacio público. 
Se debe considerar la reubicación de los elementos que están obstruyendo los flujos peatonales, para eliminar las barreras arquitectónicas y urbanas que suelen causar accidentes en la vía pública, tales como teléfonos, árboles y postes de alumbrado.

La parada del SITP necesita incorporar en su interior mobiliario accesible, como bancas, apoyos isquiáticos, carteles informativos táctiles, además de alertas visuales y auditivas sobre el sistema de rutas. Asimismo, se debe incluir señalización interna y externa con contraste cromático que identifique claramente la ubicación de la parada y el cerramiento de la misma.

Las bancas requieren el cambio de material en los asientos y espaldares por uno que brinde condiciones de termoestabilidad, junto con la instalación de apoyabrazos. Es importante reservar un espacio señalizado para la ubicación de un usuario de silla de ruedas a un costado del lugar, donde se ubique la banca, sin que se invada el sendero peatonal, y procurar que se tenga resguardo natural o adaptado ante la incidencia directa de la luz solar.

Las papeleras de basura deben ser reemplazadas debido al deterioro que presentan las actuales, por recipientes señalizados y contrastados cromáticamente con el entorno, que fomenten la cultura del reciclaje y estén elaborados teniendo en cuenta las dimensiones normativas.

Las barandillas de protección para las rampas y escaleras necesitan renovarse con el fin de resguardar la integridad física del peatón, por medio de pasamanos a doble altura, sin aristas vivas, con remates curvados, contraste cromático con el entorno, rejillas de protección y bordillos guía también contrastados visualmente.

Elementos ausentes, tales como: fuentes de agua, baterías de baños públicos y lugares adaptados para perros guía, merecen total atención, ya que son importantes para suplir las necesidades fisiológicas básicas de la ciudadanía y de asistencia para los animales que acompañan a las personas con discapacidad visual. Los baños han de incluir todos los criterios de accesibilidad normativos para personas con diversidad funcional y población vulnerable.

\section{Mejoras de señalización}

Para solucionar los inconvenientes de orientación espacial, localización y comunicación con el entorno que presenta el parque, corresponde implementar un adecuado sistema de orientación espacial o wayfinding, en el cual se incorporen todos los elementos de señalización necesarios para todas las personas, en especial aquellas con algún tipo de discapacidad sensorial o cognitiva.

Se necesita incorporar puntos de información como tótems o pedestales en los accesos al lugar, compuestos por sistemas de nomenclatura con contraste cromático, alto relieve, planos hápticos y sistema braille, complementados con información sonora.

La señalización en los itinerarios peatonales perimetrales debe contar con franjas de contraste cromático para advertir el cambio de nivel entre acera y calzada. Las zonas de juegos para niños y adultos han de tener información sobre las especificaciones técnicas y antropométricas de uso, así como colores que establezcan contraste cromático con el entorno. 
Al interior de los senderos peatonales y de la cicloruta debe existir señalización horizontal y vertical que indique el rumbo de los recorridos y advertencias de seguridad en la circulación. Se hace una mención especial al tratamiento que debe adecuarse para los cruces frontales entre estos dos flujos, con semaforización peatonal (en lo posible), rotulación pictográfica, alertas auditivas y visuales que le otorguen prioridad al flujo peatonal sobre el flujo de bicicleta.

\section{CONCLUSIONES}

Es importante entender y adoptar el "Diseño para Todos" como un nuevo paradigma al momento de proyectar las nuevas construcciones o intervenir las ya existentes, asumiéndolo como una herramienta que ha de permitir la dignificación de los sectores de la sociedad que históricamente han sido excluidos de los nodos de participación ciudadana que conforman el espacio público integrador de la ciudad. Asimismo, ha de recuperar el posicionamiento del peatón a su nivel principal dentro de la pirámide de la movilidad, el cual ha perdido por la importancia otorgada al automotor en la heredada planificación urbana y de las barreras actitudinales que, a menudo, suelen ocasionar los infractores de las normas de seguridad vial y convivencia ciudadana. De esta forma, lugares como el "Parque de los Niños" podrá garantizar que sus espacios y el equipamiento de su contexto urbano brinden:

- El acceso universal al momento de llegar al mismo.

- Ingresar con autonomía, para deambular de igual modo, todas sus instalaciones.

- Usar sin ningún tipo de obstáculos todo el mobiliario urbano, recreativo y deportivo.

- Salir sin ningún inconveniente para abordar un medio de transporte.

Esta cadena de accesibilidad que se infiere, amerita una adecuada integración con una serie de circunstancias que proporcionen la seguridad, la función, el confort y la ergonomía que requieren de manera equiparable los usuarios para optimizar la relación entre persona entorno, lo cual conducirá a mejorar su calidad de vida; acompañadas por estrategias cívicas de conservación y mantenimiento preventivo o correctivo que promuevan la apropiación y el respeto por lo público, como patrimonio material de la urbe.

Con la aplicación de estas consideraciones, llevadas al nivel de detalle en la implementación de buenas prácticas basadas en los ámbitos establecidos por las normas de accesibilidad vigentes, cuyo cumplimiento se ha de ejecutar a cabalidad y no como una sugerencia, ya que los derechos humanos y la inclusión social de la población con discapacidad y vulnerabilidad no deben asumirse como sugerentes; junto con la configuración de un plan de accesibilidad para el espacio público que permita extrapolar las buenas prácticas a otros sectores de la ciudad, se podrá contribuir de manera positiva en la transformación de una Bucaramanga enfocada en el bien común de todos sus habitantes, acorde con las directrices de sostenibilidad y conciencia medioambiental que se difunde a nivel globalizado.

\section{REFERENCIAS}

Fique, L. (2000). Accesibilidad al medio fisico y al transporte, Manual de referencia. Oficina de proyectos, Facultad de Artes. Bogotá: Universidad Nacional de Colombia. Recuperado de: http://www.snr.gob.ar/uploads/TA-Otros-02-Accesib_Medio_FisicoyTransp.pdf

IMSERSO. Fundación ONCE. Coordinadora del diseño para todas las personas en España. (2006). Libro blanco del diseño para todos en la universidad. Recuperado de: http://www. fundaciononce.es/sites/default/files/docs/libro\%2520blanco_IHt_2.pdf 
Instituto Colombiano del Deporte, Comité Paralímpico Colombiano, Asociación Colombiana de Universidades, Federación Colombiana de Organizaciones de Personas con Discapacidad Física. (2009). Guía de diseño accesible y universal. Bogotá, Colombia: Coldeportes.

Instituto Colombiano de Normas Técnicas y Certificación. (2013). Compendio. Accesibilidad para todos. Bogotá: Icontec. ISBN: 978-958-8585-36-9.

Norma Técnica Colombiana NTC 6047. (2013). Accesibilidad al medio fisico. Espacios de servicio al ciudadano en la administración pública. Requisitos. Instituto Colombiano de Normas Técnicas y Certificación. Bogotá, Colombia. Recuperado de: www.mincit.gov.co/descargar. php?id $=70802$

Reyes, M. (2009). El parque de los niños: Un verdadero bosque natural para Bucaramanga. Revista de Santander, Segunda época. (4), 66-79. Recuperado de: https://www.uis.edu.co/ webUIS/es/mediosComunicacion/revistaSantander/revista4/parqueNinos.pdf. 